\title{
Uncertainty propagation for flood forecasting in the Alps: different views and impacts from MAP D-PHASE
}

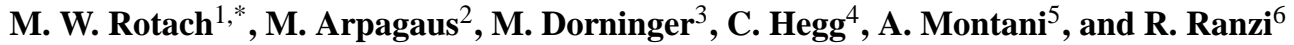 \\ ${ }^{1}$ University of Innsbruck, Institute for Meteorology and Geophysics, Innsbruck, Austria \\ ${ }^{2}$ Federal Office for Meteorology and Climatology (MeteoSwiss), Zurich, Switzerland \\ ${ }^{3}$ University of Vienna, Vienna, Austria \\ ${ }^{4}$ WSL, Swiss Federal Institute for Forest Snow and Landscape Research, Birmensdorf, Switzerland \\ ${ }^{5}$ ARPA-SIMC, Bologna, Italy \\ ${ }^{6}$ University of Brescia, Italy \\ * formerly at: Federal Office for Meteorology and Climatology (MeteoSwiss), Zurich, Switzerland \\ Correspondence to: M. W. Rotach (mathias.rotach@uibk.ac.at )
}

Received: 9 March 2012 - Accepted: 17 June 2012 - Published: 3 August 2012

\begin{abstract}
D-PHASE was a Forecast Demonstration Project of the World Weather Research Programme (WWRP) related to the Mesoscale Alpine Programme (MAP). Its goal was to demonstrate the reliability and quality of operational forecasting of orographically influenced (determined) precipitation in the Alps and its consequences on the distribution of run-off characteristics. A special focus was, of course, on heavy-precipitation events.

The D-PHASE Operations Period (DOP) ran from June to November 2007, during which an end-to-end forecasting system was operated covering many individual catchments in the Alps, with their water authorities, civil protection organizations or other end users. The forecasting system's core piece was a Visualization Platform where precipitation and flood warnings from some 30 atmospheric and 7 hydrological models (both deterministic and probabilistic) and corresponding model fields were displayed in uniform and comparable formats. Also, meteograms, nowcasting information and end user communication was made available to all the forecasters, users and end users. D-PHASE information was assessed and used by some 50 different groups ranging from atmospheric forecasters to civil protection authorities or water management bodies.

In the present contribution, D-PHASE is briefly presented along with its outstanding scientific results and, in particular, the lessons learnt with respect to uncertainty propagation. A focus is thereby on the transfer of ensemble prediction information into the hydrological community and its use with
\end{abstract}

respect to other aspects of societal impact. Objective verification of forecast quality is contrasted to subjective quality assessments during the project (end user workshops, questionnaires) and some general conclusions concerning forecast demonstration projects are drawn.

\section{Introduction}

MAP D-PHASE stands as an acronym for MAP's Demonstration of Probabilistic Hydrological and Atmospheric Simulation of Flood Events in the Alpine region. Here, MAP refers to the Mesoscale Alpine Programme (Bougeault et al., 2001), which was the World Weather Research Programme's (WWRP) first Research and Development Project (RDP). As a Forecast Demonstration Project (FDP), D-PHASE did not only constitute the fourth phase (after planning, field and evaluation phases) of MAP, but also aimed at demonstrating the success of the countless research activities during MAP (Volkert and Gutermann, 2007) in improving forecast quality with respect to research themes addressed within MAP. Specific object of this demonstration was the forecast of heavy precipitation and related flooding events in the Alpine region. An overview of D-PHASE, its goals and methods together with some outstanding scientific results can be found in Rotach et al. (2009) and Arpagaus et al. (2009), while Zappa et al. (2008) and Ranzi et al. (2009) describe some aspects 
related to hydrological processes and probabilistic hydrological real-time prediction systems implemented during D-PHASE in more detail.

D-PHASE shares interests, theme and timing with similar international efforts such as HEPEX (Schaake et al., 2006; Thielen et al., 2008) and COST-731 (Rossa et al., 2011). The former is less focused on Alpine flooding (and hence precipitation) than D-PHASE but shares the interest in ensemble hydrological approaches. The European COST action 731 on "uncertainty propagation in advanced hydro-meteorological forecast systems" not only shares much of the approaches, but also some of the (key) personnel with D-PHASE. Thus an excellent exchange between the two projects resulted in fruitful cooperation and joint use of concepts and data.

The present paper aims at giving an overview of the various results of D-PHASE - not so much in a technical sense, which are mostly published and will be referenced when necessary - but rather as a list of achievements and their meaning for future developments. Furthermore, the lessons learnt will be discussed and put into perspective. We start with a brief overview of the project in Sect. 2, describe its main results and developments that it triggered in Sect. 3, and discuss possible implications for future hydro-meteorological practice as well as research activities in Sect. 4. This will be done by assuming two different standpoints, namely that of the project (the research and organizational aspects, respectively); and that of the users of its infrastructure.

\section{D-PHASE in a nutshell}

In a technical sense, D-PHASE was a web-based experimental hydro-meteorological information system, fed in realtime by atmospheric and hydrological modelers (i.e. their products) and providers of nowcasting information, and used by decision makers (so called end-users) concerned with hydrological threats in the Alpine area, as well as the modelers themselves for self-assessment of their products. The key element of D-PHASE therefore was the so-called Visualization Platform (VP), which was operated during the "D-PHASE Operations Period" (DOP) from June to November 2007 and covered the "D-PHASE Domain" (encompassing the entire Alps and adjacent lowlands, see Fig. 2 in Rotach et al., 2009). On the VP the products of the following systems could be found:

- a total of 23 atmospheric deterministic (NWP) models, many of them at horizontal resolution of a few kilometers ("high resolution" or convection permitting models);

- seven regional atmospheric ensemble modeling systems with up to 24 members;

- 7 different hydrological modeling systems, five of which run in both ensemble mode and deterministic mode, and covering
- 43 catchments in Germany, Italy and Switzerland;

- ten different nowcasting products ranging from radar composits of different operational centers to products especially designed for D-PHASE (e.g. the "NWP minus VERA" products, comparing the NWP model output to observation-based surface analysis fields).

The key principles, according to which the VP was designed and operated, are briefly outlined in the following.

\section{Hierarchical structure}

On starting up the VP, first an overview is displayed that shows (in "traffic light color coding") for which regions a warning threshold has been reached. On clicking into any region more detail is displayed and qualitative information (which model actually exceeded the threshold, by how much and when) is available (see Fig. 1 for an example). The zooming-in can be repeated to a third, local (catchment) level where quantitative information and graphic representation (Fig. 2) of hydrological information is available. A large number of different plotting products (e.g. cross sections, time developments etc) are available for each model.

\section{Most critical is shown}

If only one model system reaches a particular threshold for a particular region or time, the color coding for this (most critical) threshold is used.

\section{Interoperability of products}

All critical definitions (thresholds) are made on a joint basis, i.e. reoccurrence periods and the assessment is performed by joint software for each of the models. The same is true for all plotting products - figures are produced by joint software with identical color coding, domain settings, etc. With this, differences between two different modeling systems actually reflect different model results and not differences in post-processing settings or definitions of thresholds.

\section{Full information to all users}

All users - and this notably includes the decision makers (end users) - are not only given the results (i.e. warning levels) but rather can see whether "red alert" in the catchment of their interest is based on the output of, say, one model and all the others do not exceed the corresponding threshold, or alternatively that a majority of models exhibit a similarly severe pattern. Thus end users get the full "ensemble based" information and can (must...) base their decision on probabilistic information by also considering their "preferred" combination of meteorological and hydrological models. 


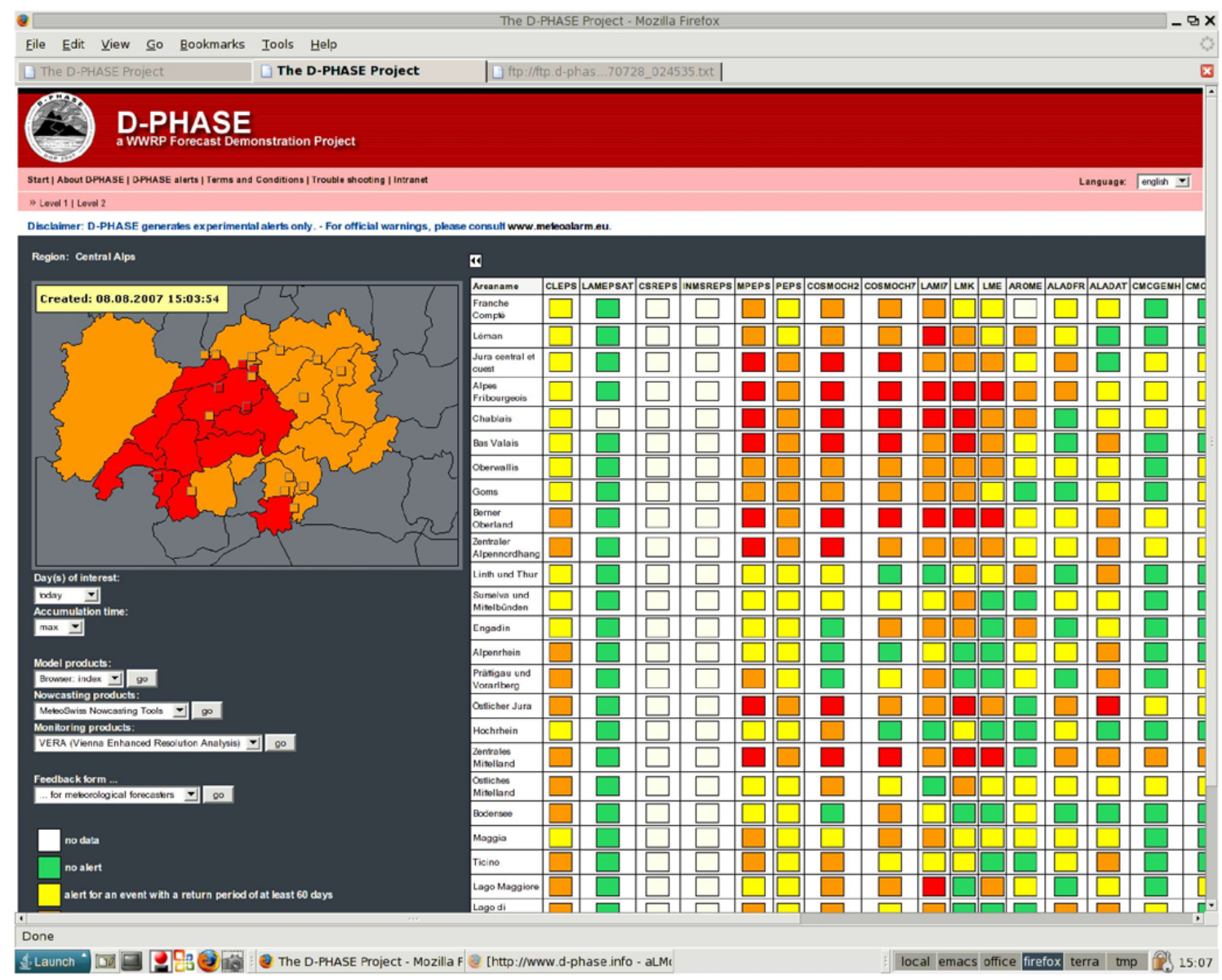

Fig. 1. Screenshot of the D-PHASE VP for 8 August 2007, level 2 (regional view). Each line corresponds to a chatchment (those visible on the map to the left) and each column informs on the results from one of the models (note that columns extend beyond those shown). Green, yellow, orange, and red areas correspond to the defined "traffic light color coding" warning levels (white indicates no information).

\section{All data archived}

In D-PHASE collaboration was established with another WWRP project named COPS, which stands for "Convective and Orographically-induced Precipitation Study" (Wulfmeyer et al., 2008, 2011). In this project an unprecedented observational data set with respect to precipitation processes in orographically-dominated terrain was gathered in southwestern Germany and northeastern France between June and August 2007, i.e. within the DOP. The two projects shared resources to archive all the data - model fields from D-PHASE and measurements from COPS - at the World Data Center for Climate in Hamburg, Germany. With this, for the first three months of the DOP and for the smaller domain of COPS, both ample model data and detailed observations are available for model validation and intercomparison, process studies and further analysis.

\section{Systematic evaluation of results, objectively}

The D-PHASE data set comprising a large number of different models at different resolutions for the same period and domain is a perfect basis for model intercomparison. Weusthoff et al. (2010) for example used the radar composite for Switzerland during the DOP to demonstrate the quantitative improvement of high-resolution (i.e. convection permitting) models when compared to their low-resolution (driving) counterparts. Bauer et al. (2011) found similar improvement of the high-resolution models when using data from COPS as a basis for verification. Ament et al. (2011) did not only investigate the usual precipitation statistics (reflecting amount, timing and distribution), but also the so-called relative ("commercial") value (Richardson, 2000). Similar to the direct precipitation statistics, they found that the highresolution models had a higher relative value ranging over a wider range of cost-loss ratios.

Concerning the verification of hydrological prediction, work has been presented by Diezig et al. (2010), Grossi et al. (2010), Ehret (2011), and Zappa et al. (2011). Diezig et 
al. (2010) presented a verification of 18 months of operational forecasts by two chains relying on the same input from COSMO-LEPS and other NWP and two different hydrological models: PREVAH and the HBV model (which is implemented at the Swiss Federal Institute for Environment). Zappa et al. (2011) studied the superposition and propagation of uncertainties by considering errors in initial conditions, in meteorological forcing and in the parameterization of the hydrological model for different events during MAP D-PHASE. Ehret (2011) focused on the evaluation of the quality of hydrological predictions in mountainous areas of the region Bavaria, and Grossi et al. (2010) verified the forecast quality during the 10-yr return period event that occurred on 24 November 2007 for the Taro River, a tributary to the Po River.

\section{Systematic evaluation of results, subjectively}

Apart from these (and many other) objective verification studies, users and end users of the VP subjectively evaluated its "services" with a view on their actual needs. Meteorological forecasters at MeteoSwiss filled in a daily questionnaire with questions regarding specific forecast issues (Rotach et al., 2009). Interestingly, the advantage of highresolution (convection permitting) atmospheric models was judged much less beneficial for the meteorological forecast than the objective verification had later proved. This suggests that objective verification scores do not always truly reflect the actual meteorological situation as sought by forecasters. Also, the forecasters appreciated the availability of singlemodel ensemble information (such as from the limited area model COSMO-LEPS (Marsigli et al., 2005; Montani et al., 2001, 2011)) much more than having at their disposition a multitude of different deterministic high-resolution models. While the "ensemble judgment" has to be made by the user $\mathrm{him} /$ herself in the latter case, apparently the usual probabilistic output (probability maps, etc.) as provided by ensemble modeling systems meets their needs. Atmospheric forecasters also appreciated the available hydrological information on the VP as a feedback to be better prepared for potential impacts to their own forecasts.

Frick and Hegg (2011) have analyzed in detail the results from questionnaires and workshops with end users (hydrological decision makers) of the VP. Clearly, end users expressed their lack of understanding with respect to probabilistic information at the outset of the DOP, but also expressed a considerable improvement due to training activities (and probably "learning on the job"). Furthermore, the detailed atmospheric and hydrological information available on the VP (as opposed to simply receiving the "level of alert") was generally appreciated by end users - especially for situation analysis some days before a possible event in their area of responsibility. For the actual decision process, considering the stress factor, most often the "usual procedures" (i.e. not using the VP information) were given preference. Most relevant with respect to the ongoing discussion on "dissemination of ensemble information" is probably the end user's appreciation of getting the full (ensemble) information and at the same time their wish to receive professional support from the atmospheric or hydrological forecasters for their interpretation (Frick and Hegg, 2011).

\section{Main achievements of D-PHASE}

At the end of D-PHASE it can probably be stated that the project achieved its primary goal, namely that of demonstrating the substantial progress in hydro-meteorological modeling in the Alpine region due to the findings and developments during MAP. For a Forecast Demonstration Project of WWRP, this is certainly the biggest achievement.

\subsection{Invaluable data set}

The data from all the model runs stored in the data archive have already been used for extensive model intercomparison and validation (see above). These intercomparisons were due to the focus of D-PHASE - mainly concerned with precipitation and run-off. Clearly, they can (and should) be extended to other variables and process chains. Especially for the subset of the COPS project (June to August 2007, COPS domain) there is, in addition to the many different model runs, a wealth of observations available (Wulfmeyer et al., 2011) that can also be used for model verification.

One particular reference data set comprising GTS and nonGTS surface station data (data from more than 10000 stations over Central Europe) has been produced, i.e. the socalled JDC (Joint D-PHASE-COPS) data set (Dorninger et al., 2009). VERA analyses for the surface fields (Steinacker et al., 2006, 2011) based on the JDC input were not only routinely used as benchmark for model assessment during the DOP (e.g. Bauer et al., 2011) but also to support process studies during COPS (Behrendt et al., 2011; Corsmeier et al., 2011) or to quantify the effect of data assimilation experiments on model results (Schwitalla et al., 2011; Bielli et al., 2011). Further, VERA analyses can also be employed for systematic posthoc model evaluation studies in the future.

\subsection{Coupled and ensemble hydrological modeling}

Due to the active participation of end-users in D-PHASE, two recent developments in the operational hydrological services in the Alpine area were certainly supported - if not triggered - by the use of the VP. The first concerns the coupling of hydrological to atmospheric models, while the second is the transfer of the ensemble modeling approach to the hydrological models themselves.

While traditionally hydrological models were forced by meteorological observations (most often at the site where the run-off needed to be predicted), a number of operational services in the alpine countries have switched to coupled 


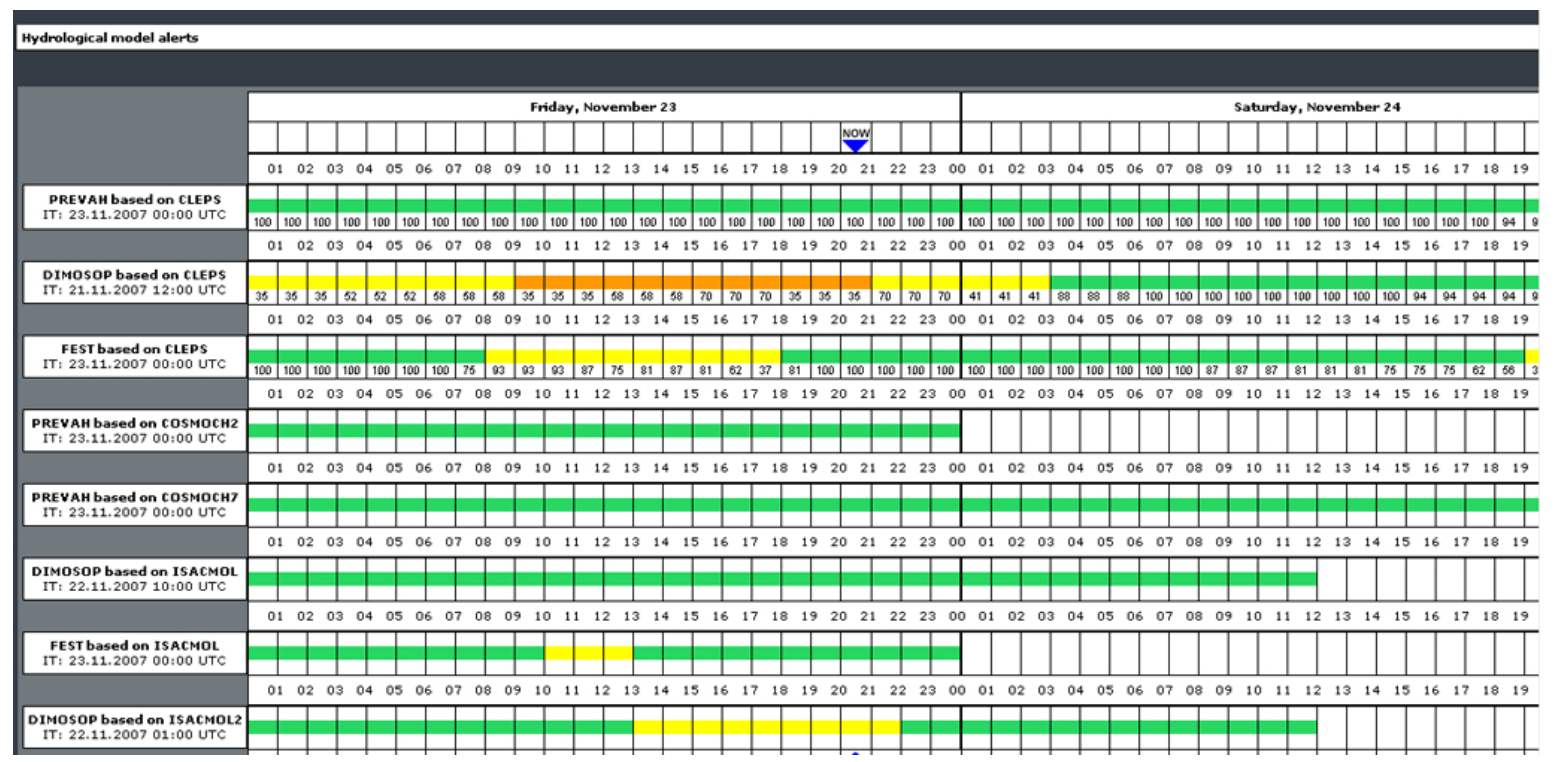

Fig. 2. Screenshot of the D-PHASE VP for 23 Novemebr 2007, level 3 (hydrological basin) for the Toce at Candoglia River, in Italy. Each of the eight lines line corresponds to a hydrological prediction chain, results from the combination of one of the three hydrological models implemented for that basin (PREVAH, DIMOSOP and FEST) forced by a meteorological prediction either in ensemble (COSMO-LEPS) or deterministic mode (COSMOCH2, COSMOCH7, ISACMOL, ISACMOL2). Green, yellow, orange (and red - not in this warning) colors correspond to the defined hydrometric warning levels. For the top three probabilistic predictions the percentage of hydrographs members with peaks in the respective warning level range is reported.

hydro-meteorological modeling in recent years, starting from experiences pioneered in the late 90s such as those developed within the MAP-SOP experiment (Bougeault et al., 2001; Ranzi et al., 2003). However this coupling happened in a very direct way with little additional interpretation. Especially the uncertainties inherent in meteorological models were not considered at all. During the DOP the awareness of these uncertainties increased and more appropriate approaches, mainly by incorporating ensemble forecasts and implementing different hydrological models in parallel, were implemented.

Ensemble hydrological modeling was, in fact, not part of the scientific program of MAP - so that "demonstrating the success of MAP" might be a little overstated with respect to this particular theme. Still, the progress that was made during MAP with limited-area ensemble modeling, and in particular COSMO-LEPS (e.g. Montani et al., 2001; Walser et al., 2004, 2006), only made it feasible to think of coupled ensemble hydro-meteorological modeling. For example, Jaun et al. (2008) coupled the runoff model PREVAH (Gurtz et al., 2003; Viviroli et al., 2009) to COSMO-LEPS to investigate hydrological ensemble prediction for the August 2005 flood in Switzerland/western Austria. The detailed information in Rotach et al. (2009), their Table 2, shows that during D-PHASE already five ensemble hydrological modeling systems were in use for real-time forecasts, most of them experimental or in test mode for later operational use.
The example of the construction work at the main train station in Zurich, Switzerland, probably best illustrates the rapid adoption of ensemble-based hydro-meteorological modeling in operational use (Addor et al., 2011). The River Sihl tunnels the train station in five huge tubes, of which two temporarily needed to be closed during the years of construction work. The river is fed from Lake Sihl, an artificial lake close to Zurich that has to be opened in case of heavy precipitation within its catchment (alert time some 4-6h), thus requiring all the five tubes to be open in order not to expose large parts of the City of Zurich to flooding. Huge potential damage costs in combination with substantial costs of false alarm and short alert times made this a perfect application of D-PHASE experience and technology. A reduced copy of the D-PHASE VP was employed in the tailored operational warning system (Addor et al., 2011) for this construction project. Moreover, COST-731 adopted this case as a "show case" for their assessment of uncertainty propagation in hydro-meteorological modeling (Zappa et al., 2010).

\subsection{Dissemination into operations}

The very philosophy and approach of D-PHASE has been used as a basis for the development of an overall warning system for natural hazards in Switzerland by different governmental offices and research institutions. This system named GIN (German acronym for "joint information platform for natural hazards") not only addresses hydrological hazards as its forerunner in D-PHASE, but adds information 
and warnings with respect to all weather hazards (storms, heat waves, icing, etc), avalanches, and is planned to even include earth-quake information in the future (Petzold et al., 2012).

The impact of D-PHASE raised the confidence of civil protection, hydro-meteorological services and water authorities (Ceppi et al., 2010; Ranzi et al., 2010) in using deterministic and probabilistic forecasting chains for operational purposes, similar to those implemented in the D-PHASE experiment also in Italy, for instance in the Po and Adige river basins and in Germany (Ehret, 2011). Some hydrographic services, already started with D-PHASE, are using the hydrological predictions to plan hydrometric measurement surveys, and reservoirs management authorities are paying more and more attention to hydro-meteorological forecasts for operations on dams.

Also, Bruen et al. (2010) show different examples of communication information on uncertainty in the framework of end-to-end flood forecasting chains.

\subsection{Demonstration triggers research}

Due to the experimental character of the VP and a large number of university institutes participating, the demonstration project (demonstrating the success and applicability of MAP research) triggered a considerable amount of novel developments and research activities. Published papers are numerous and references can be found in the final report of D-PHASE (Arpagaus et al., 2009). Here, only some of the most salient examples are mentioned.

- The radar ensemble approach (Germann et al., 2009) uses information on the uncertainty of the radar precipitation fields, which are most serious in mountainous regions due to ground clutter and obstruction, to produce error (co-)variance matrices for the observed signal and from those "ensemble of observed fields" with appropriate error statistics. Feeding these into a runoff model bears the potential to substantially improve hydrological forecasting/nowcasting, especially for small catchments and convective (local) type of precipitation (Zappa et al., 2011; Liechti et al., 2012).

- In the field of ensemble forecasting, a new limited-area ensemble prediction system, referred to as COSMOSREPS, was developed and tested during the DOP so as to improve upon the probabilistic prediction of heavy precipitation events in the short range. Verification performed during DOP showed encouraging results (Marsigli, 2009).

- In collaboration with Swiss "NCCR-Climate" activity, Fundel et al. (2010) investigated the potential of reforecasting for the COSMO-LEPS local ensemble prediction system for improved precipitation forecasts. Using 900 re-forecasts for each day in an efficient manner, they showed that a strong (up to $150 \%$ improvement in the debiased Brier skill score, Weigel et al., 2007) and highly significant improvement can be achieved using this approach. Best results were obtained for longer lead times (66-90 h) and especially the winter season.

- The close collaboration of meteorologists and hydrologists in D-PHASE also triggered the transfer of verification methodology from atmospheric to hydrological sciences (e.g. Addor et al., 2011; Jaun and Ahrens, 2009).

- The experience developed in D-PHASE in implementing hydro-meteorological forecasts over transnational river basins has been extended since the DOP over several basins, for instance the Soča-Isonzo across the border between Slovenia and Italy, and the Danube basin within the KULTURISK European Project (www.kulturisk.eu).

- Gorgas and Dorninger (2011) have introduced the idea of a NWP-model independent analysis ensemble based on observation uncertainties. The JDC data set and VERA are used as a testbed for the development of the methodology. The purpose of the analysis ensemble is to generate a probabilistic reference for the verification of NWP model outputs (Gorgas and Dorninger, 2012).

- The WWRP/WGNE Joint Working Group on Forecast Verification Research has decided to set up a second Forecast Verification Method Intercomparison Project (ICP-2) over complex terrain. ICP-2 is planned over the Alpine area under heavy use of the JDC data set. This project is currently under development.

\section{Lessons learnt}

\subsection{End users}

In many earlier projects the importance of "addressing end user's needs" has been stressed but most often as an a posteriori conclusion. When endorsing D-PHASE as WWRP FDP, the Joint Scientific Committee (JSC) of WWRP therefore recommended to make sure that "at least one real end user" was on board. If only one end user per participating hydrological catchment (43, see above) is counted, D-PHASE certainly more than fulfilled this (modest) requirement. The active participation of end users in defining the content of the VP and in particular their feedback during and after the DOP was most important for the success of this FDP. Since only a sub-group of end users actively participated from the very beginning, a somewhat more self-critical assessment would probably even state that taking (all) end users on board from the very beginning of a demonstration project is most essential. In D-PHASE it was the sequence of end user workshops - before and after the DOP - for "education, information and feedback of the end users" that proved most useful. 


\subsection{Ensemble modeling}

It has often been discussed how non-specialists - and in particular decision makers - would receive probabilistic information. Indeed they ultimately need to make a decision (yes or no), which seems to be at odds with providing probabilistic information. D-PHASE experience for hydrological decisions can be summarized as follows:

- education and training of end users - especially with respect to additional information available from ensemble forecasts - is crucial;

- providing full detail on all available information (e.g. different results from different models) is not in contradiction to the wish of end users to receive guidance on the interpretation and consequences of probabilistic information. D-PHASE end users appreciated the full information while still expressing their wish for additional guidance by the specialists to channel the multi-model information into rational decision making protocols;

- quick look (traffic color) first level information is very much appreciated and helps to efficiently use the large amount of information at hand if several models including ensemble forecasts are being used.

This experience can be taken into account when introducing ensemble forecasts in other areas such as storm, air pollution, health (e.g. heat stress, pollen), noise or other types of impact modeling from meteorological forecasts.

\subsection{International agreements}

The interoperability approach employed on the VP (equal plots, thresholds, domains and procedures from all the models) requires a high level of coordination for the warning procedures among the different participants. While D-PHASE was after all an "experimental" project, what facilitated this coordination to some extent was the implementation of its ideas into operations, revealing (re-iterating) the importance of

- data exchange (measurements and model data) among different countries or even regions,

- the coordination of warning procedures for elements that do not report to national borders

- charge-free availability of meteorological and hydrological information for the warning process.

The collection of input data and permissions for the JDC data set, in particular, was a quite cumbersome experience that should not necessarily have to be repeated for each future project of similar interest.

\subsection{Financial requirements}

D-PHASE was realized through mostly in-kind contributions of the participating institutions with only relatively modest cash funding (mostly from leftover funds of MAP) of some $50 \mathrm{k} €$. Still, the development of all the software (VP, joint graphics, etc.) has been estimated to have amounted to some $175 \mathrm{k} €$ (Arpagaus et al., 2009). Additionally, in-kind funding has been provided by MeteoSwiss for the D-PHASE project coordinator ( $50 \%$ over three years). Taking into account these costs on the one hand, and the success and extent of spin-off activities and projects from D-PHASE especially in Switzerland on the other hand, it can be concluded that supporting and coordinating a FDP or similar project does not come cost free, but still seems to be a very attractive and cost-effective way to test and establish new activities for a public service like a meteorological office.

\section{Conclusions}

In this paper an overview on the achievements of, the lessons learnt and conclusions from the WWRP forecast demonstration project D-PHASE are reported. Thus a conclusions section would essentially have to repeat the paper. It is therefore only stated here as an overall conclusion that the WWRP instrument of Forecast Demonstration Projects (WWRP, 2009) can be an effective means of not only demonstrating the success of new scientific developments, but also fostering and supporting these new developments into operations, and strengthening scientific and operational collaboration between partners from different disciplines - in the case of DPHASE mainly meteorologists and hydrologists. Preconditions include a quite moderate amount of financial resources, a team of determined people (and their employers, of course, to let them run) and, last but not least, a fascinating new development that calls for demonstration.

Acknowledgements. D-PHASE would not have been possible without the invaluable contributions of all its participants and their home institutions, which are warmly thanked here first. MeteoSwiss, the sponsor for the project coordinator position (MA) is especially thanked for its commitment and support for the project development. The collaboration with COPS, and especially the chairman of its International Scientific Steering Committee, Volker Wulfmeyer, is particularly acknowledged for the friendly collaboration - and due to the fact that it helped once more to demonstrate that the sum of two projects can be much more than just the addition of the two parts. One of the author's (RR) research was partially funded by the FP7 Project "KULTURiskProject under the Grant Agreement EC 265280. Finally, the WWRP JSC is thanked for its continuous support of the project over the years.

Edited by: A. Parodi

Reviewed by: J. Schaake and another anonymous referee 


\section{References}

Addor, N., Jaun, S., Fundel, F., and Zappa, M.: An operational hydrological ensemble prediction system for the city of Zurich (Switzerland): skill, case studies and scenarios, Hydrol. Earth Syst. Sci., 15, 2327-2347, doi:10.5194/hess-15-2327$2011,2011$.

Ament, F., Weusthoff, T., and Arpagaus, M.: Evaluation of MAP D-PHASE heavy precipitation alerts in Switzerland during summer 2007, Atmos. Res, 100, 178-189, doi:10.1016/j.atmosres.2010.06.007, 2011.

Arpagaus, M., Rotach, M. W., Ambrosetti, P., Ament, F., Appenzeller, C., Bauer, H. S., Behrendt, A., Bouttier, F., Buzzi, A., Corazza, M., Davolio, S., Denhard, M., Dorninger, M., Fontannaz, L., Frick, J., Fundel, F., Germann, U., Gorgas, T., Hegg, C., Hering, A., Keil, C., Liniger, M. A., Marsigli, C., McTaggart-Cowan, R., Montani, A., Mylne, K., Ranzi, R., Richard, E., Rossa, A., Santos-Muñoz, D., Schär, C., Seity, Y., Staudinger, M., Stoll, M., Volkert, H., Walser, A., Wang, Y., Werhahn, J., Wulfmeyer, V., and Zappa, M.: MAP D-PHASE: Demonstrating forecast capabilities for flood events in the Alpine region, Veröffentlichungen der MeteoSchweiz, 78, 75 pp., available at: http://www.meteoschweiz.admin.ch/ web/de/forschung/publikationen/meteoschweiz_publikationen/ veroeffentlichungen.html, 2009.

Bauer, H.-S., Weusthoff, T., Dorninger, M., Wulfmeyer, V., Schwitalla, T., Gorgas, T., Arpagaus, M., and Warrach-Sagi, K.: Predictive Skill of a Subset of the D-PHASE Multi-Model Ensemble in the COPS Region, Q. J. Roy. Meteorol. Soc., 137, 287305, doi:10.1002/qj.715, 2011.

Behrendt, A., Pal, S., Aoshima, F., Bender, M., Blyth, A., Corsmeier, U., Cuesta, J., Dick, G., Dorninger, M., Flamant, C., Di Girolamo, P., Gorgas, T., Huang, Y., Kalthoff, N., Khodayar, S., Mannstein, H., Träumner, K., Wieser, A., and Wulfmeyer, V.: Observation of convection initiation processes with a suite of state-of-the-art research instruments during COPS IOP8b, Q. J. Roy. Meteorol. Soc., 137, 287-305, doi:10.1002/qj.758, 2011.

Bielli, S., Grzeschik, M., Richard, E., Flamant, C., Champollion, C., Kiemle, C., Dorninger, M., and Brousseau, P.: Assimilation of water-vapour airborne lidar observations: impact study on the COPS precipitation forecasts, Q. J. Roy. Meteorol. Soc., online first, doi:10.1002/qj.1864, 2011.

Bougeault, P., Binder, P., Buzzi, A., Dirks, R., Houze, R., Kuettner, J., Smith, R. B., Steinacker, R., and Volkert, H.: The MAP Special Observing Period, B. Am. Meteorol. Soc., 82, 433-462, 2001.

Bruen, M., Krahe, P., Zappa, M., Olsson, J., Vehvilainen, B., Kok, K., and Daamen, K.: Visualizing flood forecasting uncertainty: some current European EPS platforms-COST731 working group 3, Atmos. Sci. Lett., 11, 92-99, 2010.

Ceppi, A., Ravazzani, G., Rabuffetti, D., and Mancini, M.: Evaluating the uncertainty of hydrological model simulations coupled with meteorological forecasts at different spatial scales, Procedia - Social and Behavioral Sciences, 2, 7631-7632, 2010.

Corsmeier, U., Kalthoff, N., Barthlott, C., Aoshima, F., Behrendt, A., Di Girolamo, P., Dorninger, M., Handwerker, J., Kottmeier, C., Mahlke, H., Mobbs, S. D., Norton, E. G., Wickert, J., and Wulfmeyer, V.: Processes driving deep convection over complex terrain: A multi-scale analysis of observations from COPS IOP 9c, Q. J. Roy. Meteorol. Soc., 137, 137-155, doi:10.1002/qj.754,
2011.

Diezig, R., Fundel, F., Jaun, S., and Vogt, S.: Verification of runoff forecasts by the FOEN and the WSL, in: Advances in Flood Forecasting and the Implications for Risk Management, edited by: International Commission for the Hydrology of the Rhine Basin (CHR), Alkmaar, 111-113, 2010.

Dorninger, M., Gorgas, T., Schwitalla, T., Arpagaus, M., Rotach, M. W., and Wulfmeyer, V.: Joint D-PHASE - COPS data set (JDC data set), Technical report, available at: http://imgi.uibk. ac.at/dynamics/mapdphase (last access: 25 July 2012), 2009.

Ehret, U.: Evaluation of operational weather forecasts: Applicability for flood forecasting in alpine Bavaria, Meteorol. Z., 20, 373381, 2011.

Frick, J. and Hegg, C.: Can end-users' flood management decision making be improved by information about forecast uncertainty?, Atmos. Res., 100, 296-303, doi:10.1016/j.atmosres.2010.12.006, 2011.

Fundel, F., Walser, A., Liniger, M. A., Frei, C., and Appenzeller, C.: Calibrated Precipitation Forecasts for a Limited-Area Ensemble Forecast System Using Reforecasts, Mon. Weather Rev., 138, 176-189, 2010.

Germann, U., Berenguer, M., Sempere-Torres, D., and Zappa, M.: Ensemble radar precipitation estimation for hydrology in a mountainous region, Q. J. Roy. Meteorol. Soc., 135, 445-456, doi:10.1002/qj.375, 2009.

Gorgas, T. and Dorninger, M.: Concepts for a pattern-oriented analysis ensemble based on observational uncertainties, Q. J. Roy. Meteorol. Soc., 138, 769-784, doi:10.1002/qj.949, 2011.

Gorgas, T. and Dorninger, M.: Quantifying verification uncertainty by reference data variation, Meteorol. Z., accepted, 2012.

Grossi, G., Bacchi, B., and Ranzi, R.: A real time ensemble flood forecasting in the Alps and in the Apennines, in: Analyses and images of hydrological extremes in Mediterranean environments, Proc. AMHY-FRIEND International Workshop on Hydrological Extremes, Cosenza (Italy), 10-12 July 2008, EdiBios (Ed.), Cosenza, 103-113, 2010.

Gurtz, J., Zappa, M., Jasper, K., Lang, H., Verbunt, M., Badoux, A., and Vitvar, T.: A comparative study in modelling runoff and its components in two mountainous catchments, Hydrol. Process., 17, 297-311, 2003.

Jaun, S., Ahrens, B., Walser, A., Ewen, T., and Schär, C.: A probabilistic view on the August 2005 floods in the upper Rhine catchment, Nat. Hazards Earth Syst. Sci., 8, 281-291, doi:10.5194/nhess-8-281-2008, 2008.

Jaun, S. and Ahrens, B.: Evaluation of a probabilistic hydrometeorological forecast system, Hydrol. Earth Syst. Sci., 13, 10311043, doi:10.5194/hess-13-1031-2009, 2009.

Liechti, K., Fundel, F., Germann, U., and Zappa, M.: Flood nowcasting in the Southern Swiss Alps using radar ensemble, in: Weather Radar and Hydrology, Proceedings of a symposium held in Exeter, UK, April 2011, IAHS Publ. 351, in press, 2012.

Marsigli, C., Boccanera, F., Montani, A., and Paccagnella, T.: The COSMO-LEPS mesoscale ensemble system: validation of the methodology and verification, Nonlin. Processes Geophys., 12, 527-536, doi:10.5194/npg-12-527-2005, 2005.

Marsigli, C.: COSMO-SREPS Priority Project "Short Range Ensemble Prediction System (SREPS): final report, COSMO Technical report, 13, available at: http://www.cosmo-model.org/ public/techReports.html, 2009. 
Montani, A., Marsigli, C., Nerozzi, F., Paccagnella, T., and Buizza, R.: Performance of the ARPA-SMR limited-area ensemble prediction system: two flood cases, Nonlin. Processes Geophys., 8, 387-399, doi:10.5194/npg-8-387-2001, 2001.

Montani, A., Cesari, D., Marsigli, C., and Paccagnella, T.: Seven years of activity in the field of mesoscale ensemble forecasting by the COSMO-LEPS system: main achievements and open challenges, Tellus, 63A, 605-624, doi:10.1111/j.16000870.2010.00499.x, 2011.

Petzold, I., Hess, J., Schmid, F., Arpagaus, M., and Steiner, S.: Joint Information Platform for Natural Hazards in Switzerland, Proceedings of INTERPRAEVENT 2012, Grenoble, France, $23-$ 26 April 2012, 2012

Ranzi, R., Bacchi, B., and Grossi, G.: Runoff measurements and hydrological modelling for the estimation of rainfall volumes in an alpine basin, Q. J. Roy. Meteorol. Soc., 129, 653-672, 2003.

Ranzi, R., Bacchi, B., Ceppi, A., Cislaghi, M., Ehret, U., Jaun, S., Marx, A., Hegg, C., and Zappa, M.: Real-time demonstration of hydrological ensemble forecasts in MAP D-PHASE, La-HouilleBlanche, 5, 95-103, doi:10.1051/lhb/2009061, 2009.

Richardson, D. S.: Skill and relative economi value of the ECMWF ensemble prediction system, Q. J. Roy. Meteorol. Soc., 126, 649667,2000

Rossa, A., Liechti, K., Zappa, M., Bruen, M., Germann, U., Haase, G., Keil, C., and Krahe, P.: The COST 731 action: a review on uncertainty propagation in advanced hydrometeorological forecast systems, Atmos. Res., 100, 150-167, doi:10.1016/j.atmosres.2010.11.016, 2011.

Rotach, M. W., Ambrosetti, P., Ament, F., Appenzeller, C., Arpagaus, M., Bauer, H. S., Behrendt, A., Bouttier, F., Buzzi, A., Corazza, M., Davolio, S., Denhard, M., Dorninger, M., Fontannaz, L., Frick, J., Fundel, F., Germann, U., Gorgas, T., Hegg, C., Hering, A., Keil, C., Liniger, M. A., Marsigli, C., McTaggart-Cowan, R., Montani, A., Mylne, K., Ranzi, R., Richard, E., Rossa, A., Santos-Muñoz, D., Schär, C., Seity, Y., Staudinger, M., Stoll, M., Volkert, H., Walser, A., Wang, Y., Werhahn, J., Wulfmeyer, V., and Zappa, M.: MAP DPHASE: Real-time Demonstration of Weather Forecast Quality in the Alpine Region, B. Am. Meteorol. Soc., 90, 1321-1336, doi:10.1175/2009BAMS2776.1, 2009.

Schaake, J., Franz, K., Bradley, A., and Buizza, R.: The Hydrologic Ensemble Prediction EXperiment (HEPEX), Hydrol. Earth Syst. Sci. Discuss., 3, 3321-3332, doi:10.5194/hessd-3-33212006, 2006.

Schwitalla, T., Bauer, H.-S., Wulfmeyer, V., and Aoshima, F.: Highresolution simulation over central Europe: assimilation experiments during COPS IOP 9c, Q. J. Roy. Meteorol. Soc., 137, 156175, doi:10.1002/qj.721, 2011.

Steinacker, R., Ratheiser, M., Bica, B., Chimani, B., Dorninger, M., Gepp, W., Lotteraner, C., Schneider, S., and Tschannett, S.: A Mesoscale Data Analysis and Downscaling Method over Complex Terrain, Mon. Weather Rev., 134, 2578-2771, 2006.

Steinacker, R., Mayer, D., and Steiner, A.: Data quality control based on self-consistency, Mon. Weather Rev., 139, 3974-3991, 2011

Thielen, J., Schaake, J., Hartman, R., and Buizza, R.: Aims, challenges and progress of the Hydrological Ensemble Prediction Experiment (HEPEX) following the third HEPEX workshop held in Stresa 27 to 29 June 2007, Atmos. Sci. Lett., 9, 29-35, doi:10.1002/asl.168, 2008

Viviroli, D., Zappa, M., Gurtz, J., and Weingartner, R.: An introduction to the hydrological modelling system PREVAH and its preand post-processing-tools, Environ. Modell. Softw., 24, 1209$1222,2009$.

Volkert, H. and Gutermann, T.: Inter-domain cooperation for mesoscale atmospheric laboratories: The Mesoscale Alpine Programme as a rich study case, Q. J. Roy. Meteorol. Soc., 133, 949-968, 2007.

Walser, A., Arpagaus, M., Appenzeller, C., and Leuchtbecher, M.: The impact of moist singular vectors and horizontal resolution on short-range limited-area ensemble forecasts for two European winter storms, Mon. Weather Rev., 134, 2877-2887 doi:10.1175/MWR3210.1, 2006.

Walser, A., Luthi, D., and Schar, C.: Predictability of precipittion in a cloud resolving model, Mon. Weather Rev., 132, 560-577, doi:10.1175/1520-0493(2004)132<0560:POPIAC > 2.0.CO;2, 2004.

Weigel, A. P., Liniger, M. A., and Appenzeller, C.: The discrete Brier and ranked probability skill scores, Mon. Weather Rev., 135, 118-124, 2007.

Weusthoff, T., Ament, F., Arpagaus, M., and Rotach, M. W.: Assessing the benefits of convection permitting models by Neighborhood Verification - examples from MAP D-PHASE, Mon. Weather Rev., 138, 3418-3433, doi:10.1175/2010_MWR3380.1, 2010.

Wulfmeyer, V., Behrendt, A., Bauer, H. S., Kottmeier, C., Corsmeier, U., Blyth, A., Craig, G., Schumann, U., Hagen, M., Crewell, S., Di Girolamo, P., Flamant, C., Miller, M., Montani, A., Mobbs, S., Richard, E., Rotach, M. W., Arpagaus, M., Russchenberg, H., Schlüssel, P., König, M., Gärtner, V., Steinacker, R., Dorninger, M., Turner, D. D., Weckwerth, T., Hense, A., and Simmer, C.: The Convective and Orographically-induced Precipitation Study: A Research and Development Project of the World Weather Research Program for improving quantitative precipitation forecasting in low-mountain regions, B Am. Meteorol. Soc., 89, 1477-1486, doi:10.1175/2008BAMS2367.1, 2008.

Wulfmeyer, V., Behrendt, A., Kottmeier, C., Corsmeier, U., Barthlott, C., Craig, G. C., Hagen, M., Althausen, D., Aoshima, F., Arpagaus, M., Bauer, H. S., Bennett, L., Blyth, A., Brandau, C., Champollion, C., Crewell, C., Dick, G., Di Girolamo, P., Dorninger, M., Dufournet, Y., Eigenmann, R., Engelmann, R., Flamant, C., Foken, T., Gorgas, T., Grzeschik, M., Handwerker, J., Hauck, C., Hoeller, H., Junkermann, W., Kalthoff, N., Kiemle, C., Klink, S., Koenig, M., Krauss, L., Long, C. N., Madonna, F., Mobbs, S., Neininger, B., Pal, S., Peters, G., Pigeon, G., Richard, E., Rotach, M. W., Russchenberg, H., Schwitalla, T., Smith, V., Steinacker, R., Trentmann, J., Turner, D. D., van Baelen, J., Vogt, S., Volkert, H., Weckwerth, T., Wernli, H., Wieser, A., and Wirth, A.: The Convective and Orographically-induced Precipitation Study (COPS): the scientific strategy, the field phase, and research highlights, Q. J. Roy. Meteorol. Soc., 137, 3-30, doi:10.1002/qj.752, 2011.

WWRP: Stategic Plan for the implementation of the WMO's World Weather Research Programme (WWRP), 2, availabe at: http://www.wmo.int/pages/prog/arep/wwrp/new/documents/ final_WWRP_SP_6_Oct.pdf, 2009.

Zappa, M., Rotach, M. W., Arpagaus, M., Dorninger, M., Hegg, C., Montani, A., Ranzi, R., Ament, F., Germann, U., Grossi, 
G., Jaun, S., Rossa, A., Vogt, S., Walser, A., and Wunram, C.: MAP D-PHASE: Real-time demonstration of hydrological ensemble prediction systems, Atmos. Sci. Lett., 2, 80-87, doi:10.1002/asl.183, 2008.

Zappa, M., Jaun, S., Germann, U., Walser, A., and Fundel, F.: Superposition of three sources of uncertainties in operational flood forecasting chains, Atmos. Res., 100, 246-262, doi:10.1016/j.atmosres.2010.12.005, 2011.
Zappa, M., Beven, K. J., Bruen, M., Cofino, A. S., Kok, K., Martin, E., Nurmi, P., Orfila, B., Roulin, E., Schröter, K., Seed, A., Szturc, J., Vehviläinen, B., Germann, U., and Rossa, A.: Propagation of uncertainty from observing systems and NWP into hydrological models: COST-731 Working Group 2, Atmos. Sci. Lett., 11, 83-91, 2010.

Zappa, M., Jaun, S., Germann, U., Walser, A., and Fundel, F.: Superposition of three sources of uncertainties in operational flood forecasting chains, Atmos. Res., 100, 246-262, 2011. 